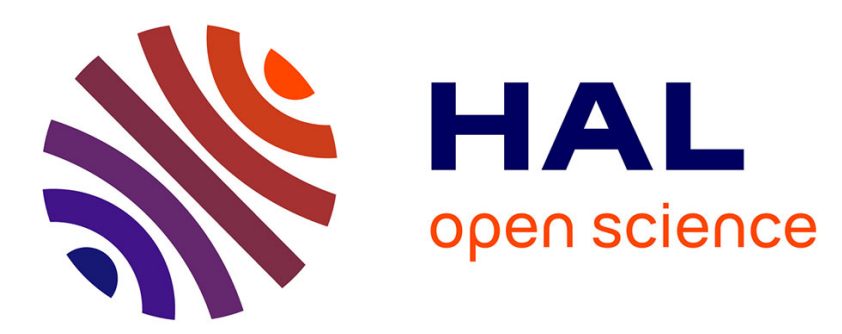

\title{
Intra-crystalline mesoporous ZSM-5 zeolite by grinding synthesis method
}

Yu Gu, Xiaohui Wang, Zhengxing Qin, Svetlana Mintova, Xinmei Liu

\section{To cite this version:}

Yu Gu, Xiaohui Wang, Zhengxing Qin, Svetlana Mintova, Xinmei Liu. Intra-crystalline mesoporous ZSM-5 zeolite by grinding synthesis method. Microporous and Mesoporous Materials, 2020, 306, pp.110437. 10.1016/j.micromeso.2020.110437 . hal-03016617

\section{HAL Id: hal-03016617 https://hal.science/hal-03016617}

Submitted on 27 Nov 2020

HAL is a multi-disciplinary open access archive for the deposit and dissemination of scientific research documents, whether they are published or not. The documents may come from teaching and research institutions in France or abroad, or from public or private research centers.
L'archive ouverte pluridisciplinaire HAL, est destinée au dépôt et à la diffusion de documents scientifiques de niveau recherche, publiés ou non, émanant des établissements d'enseignement et de recherche français ou étrangers, des laboratoires publics ou privés. 


\title{
Intra-crystalline mesoporous ZSM-5 zeolite by
}

\section{grinding synthesis method}

\author{
Yu Gu , Xiaohui Wang ${ }^{\mathrm{a}}$, Zhengxing Qina ${ }^{\mathrm{a}}$, Svetlana Mintova ${ }^{\mathrm{ab}}$, and Xinmei Liu ${ }^{* a}$ \\ ${ }^{a}$ State Key Laboratory of Heavy Oil Processing, College of Chemical Engineering, China \\ University of Petroleum (East China), Qingdao, 266580, China \\ ${ }^{b}$ Normandie University, ENSICAEN, UNICAEN, CNRS, Laboratoire Catalyse et Spectrochimie, \\ 14000 Caen, France \\ * Corresponding author \\ E-mail: 1xmei@upc.edu.cn
}

\begin{abstract}
ZSM-5 zeolite with intra-crystalline mesopores was synthesized via grinding synthesis method (GSM). It was found that the formation of the mesopores in the ZSM-5 crystals is due to the difference between the speed of crystallization and dissolution processes occurring during the GSM synthesis. The alkalinity of the precursor gels tailored the formation of the mesoporous structure and the crystal size of the ZSM-5 zeolite. The most regular mesopores in the ZSM-5 crystals were formed under grinding synthesis of the precursor gel with a defined concentration of alkali cations $\left(\mathrm{Na}_{2} \mathrm{O} / \mathrm{SiO}_{2}=0.113\right)$. The size of the mesopores in the ZSM-5 crystals varied from
\end{abstract}


$3 \mathrm{~nm}$ to $25 \mathrm{~nm}$, while the size of the individual ZSM-5 crystallites is in the range of $50-300 \mathrm{~nm}$ which depend mainly on the amount of $\mathrm{NaOH}$ in the precursor gel.

Keywords: ZSM-5 zeolite, grinding synthesis method (GSM), intra-crystalline mesopores, in-situ generation, $\mathrm{NaOH} / \mathrm{Si}$ regulation

\section{Introduction}

As first synthesized by Mobil Corp in the 1970s, ZSM-5 zeolite has been extensively applied in various industrial processes such as catalysis and gas separation, owing to its unique porosity. However, conventional microporous ZSM-5 suffers from a limited diffusion path, which restricts its applications. The mesoporous or hierarchical structure of ZSM-5 was usually constructed via post synthesis, acid/base treatment, hydrothermal dealumination and mesoporous-OSDA induced growth, etc. ${ }^{14}$, in order to enhance mass transfer and accessibility of active sites. These treatment procedures complicate the synthesis process and lead to extra costs and loss of materials. Recently $\mathrm{Yu}$ et al. reported an amino acid assisted construction of hierarchical single-crystalline ZSM-5, where two-step crystallization process was applied. Besides, the synthesis was performed in a precursor gel with a high $\mathrm{Si} / \mathrm{Al}$ ratio over 150 . So far, in-situ generation of mesopores in ZSM-5 zeolites without any other treatment during crystallization is rarely reported ${ }^{6 s}$.

Conventional hydrothermal crystallization of high silica zeolites leads to substantial waste water discharge by using a large amount of templates and solvents. While the dry gel conversion (DGC) or atmospheric pressure synthesis could efficiently reduce water usage, but extra steps are needed to evaporate solvents, which consumes additional energy ${ }^{9.11}$. Xiao et al. developed a solid-state synthesis of zeolites, which reduced the used of solvent considerably ${ }^{12,13}$. 
Here we present a facile grinding synthesis method (GSM), which involves mixing raw materials and grinding in a mortar, thus resulting in intra-crystalline mesoporous ZSM-5 zeolites with a $\mathrm{Si} / \mathrm{Al}$ ratio of 15 . No mesoporous templates nor pre- or post-treatments were applied in the GSM, which considerably simplify the preparation process for hierarchical zeolitic materials.

\section{Results and discussion}

\section{Observation of intra-crystalline mesopores}

The synthesis details and characterization of the samples are presented in the experimental section in SI. The samples prepared by GSM from precursor gels with different alkalinity and for different crystallization time are summarized in Table S1. The intra-crystalline mesoporous Z5P sample was prepared from a precursor gel with a $\mathrm{Na}_{2} \mathrm{O} / \mathrm{SiO}_{2}$ ratio of 0.113 and crystallization time of 24 hours. The diffraction pattern of the Z5P sample is presented in Fig. 1a; all characteristic peaks of MFI type zeolite are present. The $\mathrm{Si} / \mathrm{Al}$ of the intra-crystalline mesoporous $\mathrm{Z5P}$ sample determined by XRF is 16.5 , which is slightly higher than the precursor gel with a $\mathrm{Si} / \mathrm{Al}$ ratio of 15 , implying almost full conversion of the amorphous into crystalline matter. The $\mathrm{N}_{2}$ physisorption isotherm of sample Z5P is typical type IV with hysteresis loop at $\mathrm{P} / \mathrm{P}_{0}=0.4-0.9$ (Fig. 1b). The $\mathrm{BJH}$ pore size distribution curve presented as an inset indicates two distinct types of mesopores of approximately 3-8 $\mathrm{nm}$ and $25 \mathrm{~nm}$. The intra-crystalline mesoporous Z5P sample has a mesopore area and mesopore volume of $77 \mathrm{~m}^{2} / \mathrm{g}$ and $0.20 \mathrm{~cm}^{3} / \mathrm{g}$, respectively (Table 1). The micropore volume is $0.15 \mathrm{~cm}^{3} / \mathrm{g}$, which is typical for ZSM-5 zeolite with similar Si/Al ratio as reported

previously $^{14,15}$. The particle size and morphology of the crystals were examined by TEM and SEM (Fig. 1c and Fig. S1). The sample Z5P contains both small crystals less than 100nm and bigger ones over $200 \mathrm{~nm}$. Fig. 1d shows the intra-crystalline mesopores in the smaller crystals of sample 
Z5P. Mesopores with irregular shapes are seen within the ZSM-5 crystals. The size of these mesopores is in the range of $5-25 \mathrm{~nm}$. This is in line with the pore size distribution measured by $\mathrm{N}_{2}$-physisorption of Z5P (Fig. 1b, Inset).

The crystal growth of zeolites is controlled by a dynamic equilibrium between crystallization and dissolution ${ }^{16-19}$. The precursor suspension used for the GSM synthesis contains high concentration of $\mathrm{NaOH}$ and thus the alkalinity is higher compared with the precursor gel used for conventional hydrothermal synthesis of ZSM-5. The high concentration of $\mathrm{NaOH}$ increased not only the crystallization rate, but also the dissolution of the formed zeolite crystals. Especially smaller crystals in metastable state, having higher interface energy, are easier to be dissolved at high $\mathrm{pH}$. Hence, when the dissolution speed is faster than that of the crystallization, mesopores are expected to be generated. Thus we believe that the formation of the mesopores can be ascribed to the dissolution of the zeolite crystallites.

\section{Tuning the intra-crystalline mesoporous structure}

The mesopore formation in zeolite crystals from precursor gels with different $\mathrm{Na}_{2} \mathrm{O} / \mathrm{SiO}_{2}$ ratio was studied in details. Two samples, denoted as $1.5 \mathrm{Na}-\mathrm{Z} 5$ and $2.0 \mathrm{Na}-\mathrm{Z} 5$, from precursor gels with 1.5-fold and 2-fold $\mathrm{NaOH}$ amount in comparison to sample Z5P, were synthesized by GSM (Table $\mathrm{S} 1, \mathrm{Na}_{2} \mathrm{O} / \mathrm{SiO}_{2}=0.153$ and 0.193 , respectively). The XRD results of samples $1.5 \mathrm{Na}-\mathrm{Z} 5$ and $2.0 \mathrm{Na}-$ Z5 confirmed that pure ZSM-5 is successfully prepared even at higher $\mathrm{pH}$ (Fig. S2). Higher alkalinity can remarkably promote crystal growth as well ${ }^{2022}$. This is verified by the increased crystal size of $1.5 \mathrm{Na}-\mathrm{Z} 5$ and $2.0 \mathrm{Na}-\mathrm{Z} 5$ as shown in the SEM images (Fig. S3). The mesopores gradually decrease until totally disappear in sample $2.0 \mathrm{Na}-\mathrm{Z} 5$, which is synthesized with the highest $\mathrm{NaOH}$ content (Fig. 2). The absence of mesopores is further validated by $\mathrm{N}_{2}$-physisorption result presented in Fig. 3. The mesopore specific area and mesopore volume also decreased sharply as 
increasing the $\mathrm{NaOH}$ amount (Table 1). The ZSM-5 zeolite synthesized from the precursor gel with higher alkalinity (e.g., 1.5Na-Z5) bear larger crystal size and fewer intra-crystalline mesopores. At this condition the precursor gel would be further dissolved, thus high concentrated silica and alumina species would supply much more abundant nutrients, which would significantly accelerate the growth of the crystals. Sang et.al claimed that more stable mordenite (MOR) phase or even $\alpha$-quartz would form from highly alkaline precursor gels used for the synthesis of ZSM$5^{23}$. Hence, in the current case, ZSM-5 crystals with bigger size are formed instead of being partially dissolved, leading to the decrease and even disappearance of the intra-crystalline mesopores.

The above results demonstrate that high alkalinity had significant influence on the morphology and intra-crystal mesopores formation of ZSM-5 crystals. Therefore, zeolite samples were synthesized from precursor gels with lower alkalinity (Fig. S4) and denoted as samples $0.25 \mathrm{Na}-$ $\mathrm{Z5}$ and $0.5 \mathrm{Na}-\mathrm{Z} 5$, respectively (Table $\mathrm{S} 1, \mathrm{Na}_{2} \mathrm{O} / \mathrm{SiO}_{2}=0.053$ and 0.073 , respectively). No mesopores were found in the two samples (Fig. 4). Another interesting change is observed in the morphological features of the samples synthesized at low $\mathrm{pH}$ of the precursor gel. ZSM-5 crystals with a nano-stick morphology are formed, and the crystal size is considerably reduced to approximate 50nm (Fig. 4b and 4d). These observations were confirmed by SEM (Fig. 5), showing that the zeolite samples consist of nano-sticks with a width of less than 100nm, which is smaller than the crystal size of sample Z5P (larger than 200nm). The absence of the mesopores in the $0.25 \mathrm{Na}-\mathrm{Z} 5$ and $0.5 \mathrm{Na}-\mathrm{Z} 5$ zeolites synthesized at lower alkalinity is due to the inhibition of dissolution by a $\mathrm{OH}^{-}$shortage. In this case, crystallization process dominates, leading to the formation of pure microporous zeolites. 
To further verify that the mesopore intra-crystalline structure was in-situ generated mainly by the crystallization-dissolution imbalance, we performed the synthesis of zeolite using the precursor gel of Z5P sample for various crystallization time. Samples were denoted as Z5-yh, where y represented the real crystallization time (Table S1, Z5-6h, Z5-12h, Z5-18h, Z5-48h and Z5-96h). No crystalline product was obtained from the precursor gel via GSM before $12 \mathrm{~h}$, as the XRD pattern corresponds to pure amorphous matter (Fig. S5, Z5-6h). On the other hand, almost the same crystallinity and porosity of samples Z5-12h and Z5P are measured (Fig. S5 and Table 1). Prolonging the crystallization time to $48 \mathrm{~h}$ and $96 \mathrm{~h}$ has no obvious effect on the crystallinity (Fig. S5) and morphology (Fig. S6c and S6d) of the samples.

TEM image of sample Z5-12h (Fig. 6a) demonstrates that the intra-crystalline mesopores are already generated within $12 \mathrm{~h}$, confirmed by the hysteresis loop observed in $\mathrm{N}_{2}$ physisorption isotherms (Fig. 7). Increase of the crystallization time up to $96 \mathrm{~h}$ led to the formation of bigger mesopores and partial formation of macropores over 50nm (Z5-96h, Fig. 6d). The mesopore volume of sample Z5-96h is slightly higher than that of samples Z5-12h and Z5P (Table 1), which is ascribed to the faster dissolution than crystallization when the synthesis time is extended.

The crystallization-dissolution imbalance leading to the formation of mesoporous ZSM-5 zeolite is presented in Scheme 1. At lower alkalinity (region I ), the dissolution rate is slower than the crystallization rate, leading to the formation of microporous ZSM-5 (e.g., sample 0.5Na-Z5). Further increase of the alkalinity substantially accelerates the dissolution and surpasses the crystallization (region II). This would lead to formation of partial defects or mesopores in the crystals (e.g., sample Z5P). At higher alkalinity (region III), the precursor gel would be dissolved much faster, thus facilitating the crystal growth over concomitant dissolution, hence no mesopores 
could be generated (e.g., sample 2.0Na-Z5). Besides, prolonging crystallization time would slightly increase the size of the mesopores formed, but the effect is not apparent.

\section{Conclusions}

The grinding synthesis method (GSM) is an appropriate approach towards creation of an intracrystalline mesoporous ZSM-5 zeolite. The formation of the mesoporous zeolite structure is attributed to the imbalance between the crystallization and dissolution rates, and is mainly controlled by the alkalinity of the precursor gel. Even though the constructed mesopores were irregular in shape and size, and not uniformly distributed among the crystals, it reveals the possibilities to generate the intra-crystalline mesoporous zeolite structure by one-step synthesis procedure. This finding would stimulate the development of more rational approaches towards preparation of hierarchical zeolites.

\section{Conflicts of interest}

There are no conflicts to declare.

\section{Acknowledgments}

This work was supported by the National Natural Science Foundation of China (Grant No. 21978326, 21991091) and the Natural Science Foundation of Shandong Province (Grant No. ZR2019MB029).

\section{Notes and references}

1. Z. Qin, L. Pinard, M. A. Benghalem, T. J. Daou, G. Melinte, O. Ersen, S. Asahina, J.-P. Gilson and V. Valtchev, Chemistry of Materials, 2019, 31, 4639-4648.

2. Z. Qin, L. Lakiss, J. P. Gilson, K. Thomas, J. M. Goupil, C. Fernandez and V. Valtchev, Chemistry of Materials, 2013, 25, 2759-2766.

3. F. Schmidt, M. R. Lohe, B. Büchner, F. Giordanino, F. Bonino and S. Kaskel, Microporous and Mesoporous Materials, 2013, 165, 148-157.

4. M. Milina, S. Mitchell, N.-L. Michels, J. Kenvin and J. Pérez-Ramírez, Journal of Catalysis, 2013, 308, 398-407. 
5. Q. Zhang, A. Mayoral, O. Terasaki, Q. Zhang, B. Ma, C. Zhao, G. Yang and J. Yu, Journal of the American Chemical Society, 2019, 141, 3772-3776.

6. K. Zhang, Y. Liu, J. Zhao and C. Liu, Chinese Journal of Chemistry, 2012, 30, 597-603.

7. W. Li, T. Ma, Y. Zhang, Y. Gong, Z. Wu and T. Dou, CrystEngComm, 2015, 17, 56805689.

8. Z. L. Hua, J. Zhou and J. L. Shi, Chemical communications, 2011, 47, 10536-10547.

9. Y. Liu, X. Cui, L. Han, Z. Yu and X. Liu, Microporous and Mesoporous Materials, 2014, 198, 230-235.

10. K. Shen, N. Wang, W. Qian, Y. Cui and F. Wei, Catalysis Science \& Technology, 2014, 4, 3840-3844.

11. Y. Lyu, Y. Liu, X. He, L. Xu, X. Liu and Z. Yan, Applied Surface Science, 2018, 453, 350-357.

12. L. Ren, Q. Wu, C. Yang, L. Zhu, C. Li, P. Zhang, H. Zhang, X. Meng and F. S. Xiao, Journal of the American Chemical Society, 2012, 134, 15173-15176.

13. C. Zhang, Q. Wu, C. Lei, S. Pan, C. Bian, L. Wang, X. Meng and F.-S. Xiao, Industrial \& Engineering Chemistry Research, 2017, 56, 1450-1460.

14. M. Razavian, S. Fatemi and M. Komasi, Materials Research Bulletin, 2015, 65, 253-259.

15. M. T. Portilla, F. J. Llopis and C. Martínez, Catal. Sci. Technol., 2015, 5, 3806-3821.

16. Z. Nagy, E. Aamir and C. Rielly, Crystal growth \& design, 2011, 11, 2205-2219.

17. L. Ding, Y. Zheng, Z. Zhang, Z. Ring and J. Chen, Microporous and Mesoporous Materials, 2006, 94, 1-8.

18. V. Nikolakis, D. G. Vlacho and M. Tsapatsis, Microporous and Mesoporous Materials, 1998, 21, 337-346.

19. G. Feng, P. Cheng, W. Yan, M. Boronat, X. Li, J.-H. Su, J. Wang, Y. Li, A. Corma, R. $\mathrm{Xu}$ and $\mathrm{J}$. Yu, Science, 2016, 351, 1188-1191.

20. E. M. Flanigen, in Molecular Sieves, AMERICAN CHEMICAL SOCIETY, 1973, vol. 121, ch. 10, pp. 119-139.

21. A. J. H. P. van der Pol and J. H. C. van Hooff, Applied Catalysis A: General, 1992, 92, 93-111.

22. M. A. Uguina, A. de Lucas, F. Ruiz and D. P. Serrano, Industrial \& Engineering Chemistry Research, 1995, 34, 451-456.

23. S. Sang, F. Chang, Z. Liu, C. He, Y. He and L. Xu, Catalysis Today, 2004, 93-95, 729734. 


\section{Graphical abstract}

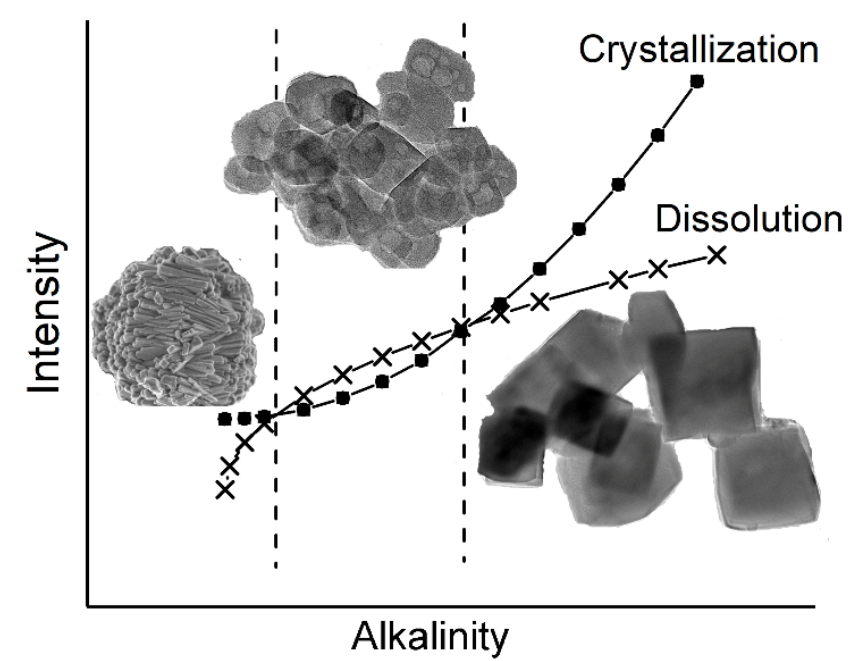




\section{Figures}
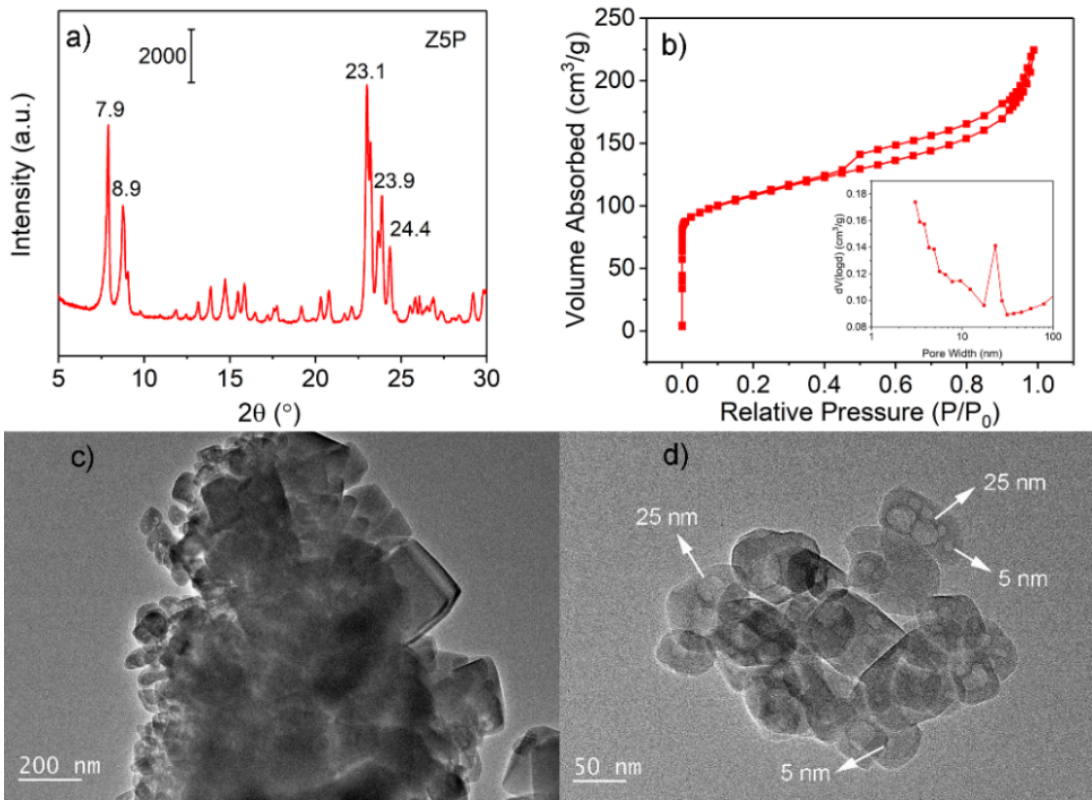

Fig. 1. (a) XRD pattern, (b) $\mathrm{N}_{2}$ physisorption isotherm (inset: BJH pore size distribution), and TEM images (c) Scale bar, $M=200 \mathrm{~nm}$, (d) Scale bar, $\mathrm{M}=50 \mathrm{~nm}$ of sample Z5P.

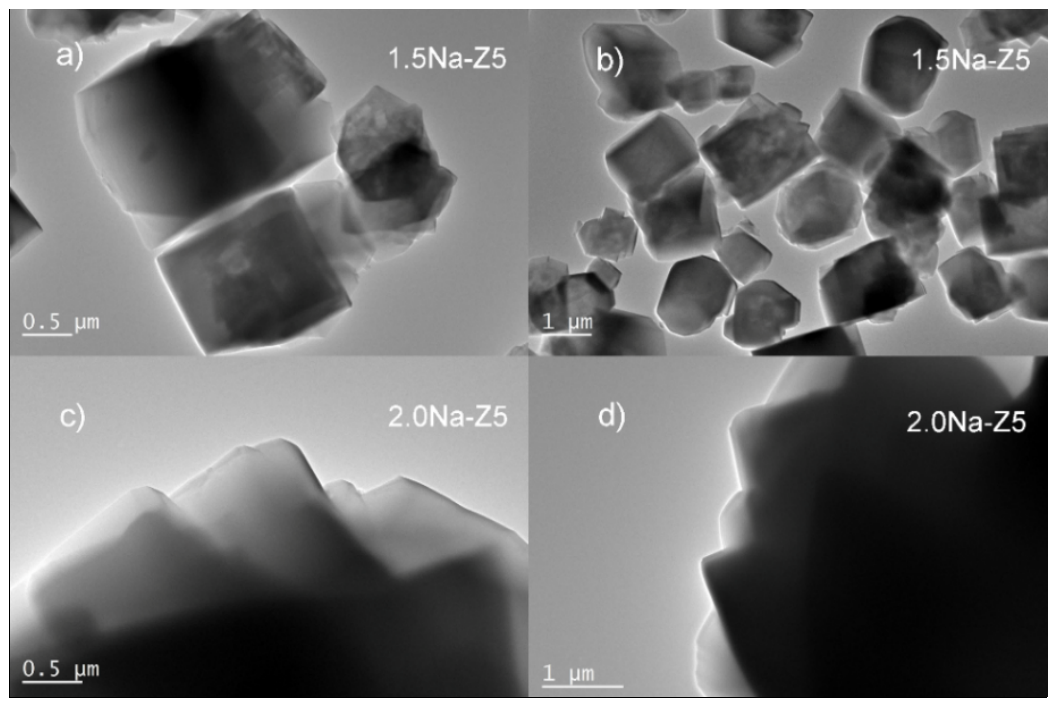

Fig. 2. TEM images of samples (a) $1.5 \mathrm{Na}-\mathrm{Z} 5$, scale bar, $\mathrm{M}=0.5 \mu \mathrm{m}$; (b) $1.5 \mathrm{Na}-\mathrm{Z} 5$, scale bar, $\mathrm{M}=1 \mu \mathrm{m}$; (c) $2.0 \mathrm{Na}-\mathrm{Z} 5$, scale bar, $\mathrm{M}=0.5 \mu \mathrm{m}$; and (d) $2.0 \mathrm{Na}-\mathrm{Z} 5$, scale bar, $\mathrm{M}=1 \mu \mathrm{m}$. 


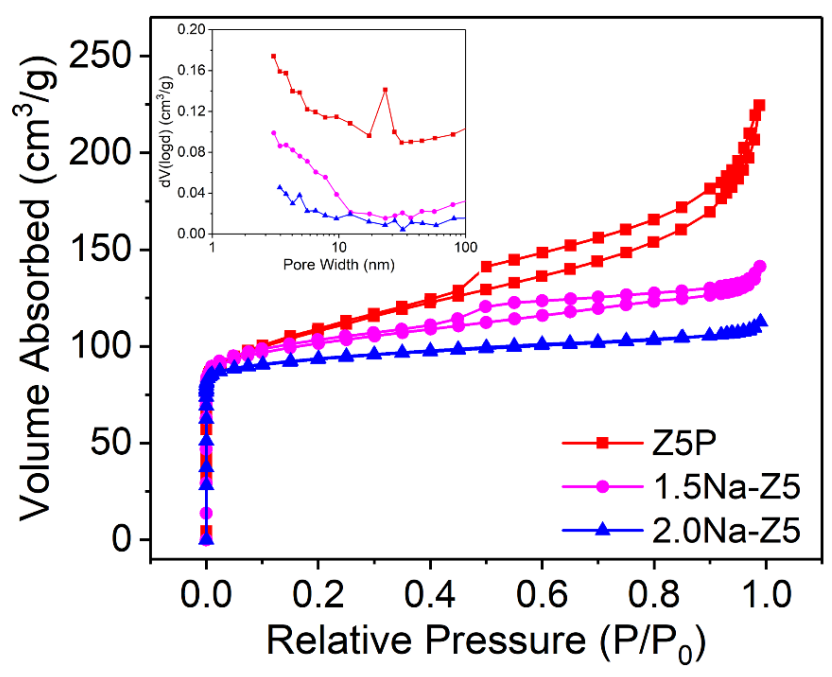

Fig. 3. $\mathrm{N}_{2}$-physisorption isotherms and $\mathrm{BJH}$ pore size distributions (Inset) of samples Z5P, 1.5Na$\mathrm{Z} 5$ and $2.0 \mathrm{Na}-\mathrm{Z} 5$.

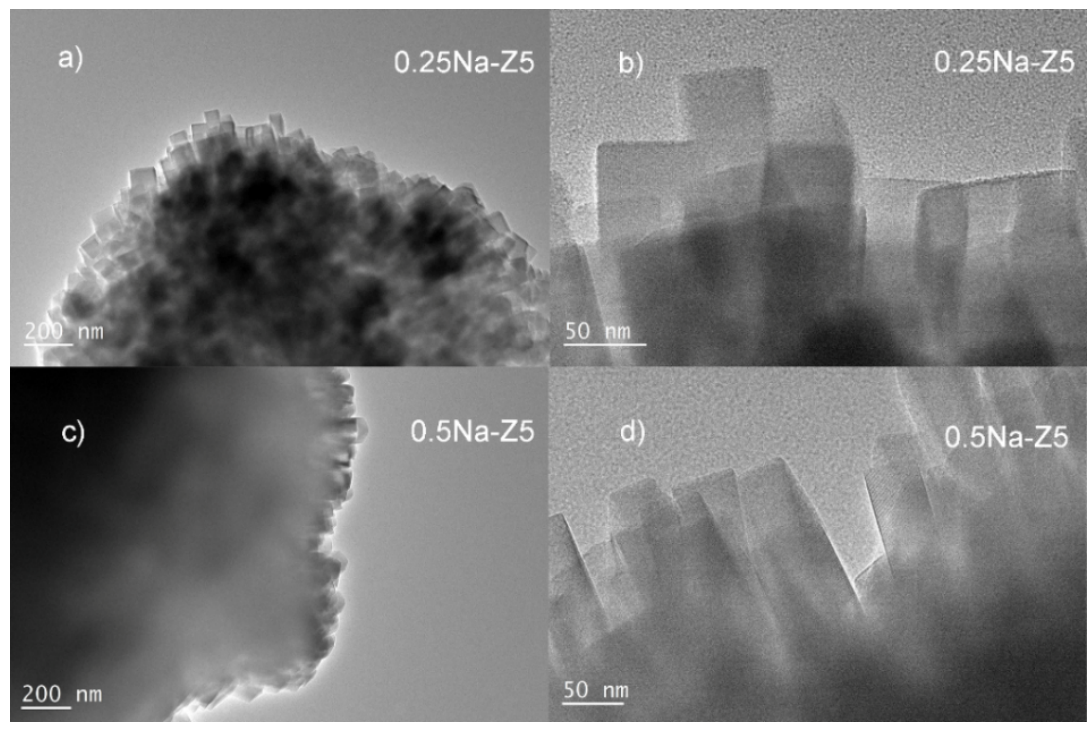

Fig. 4. TEM images of samples (a) $0.25 \mathrm{Na}-\mathrm{Z}$, scale bar, $\mathrm{M}=200 \mathrm{~nm}$; (b) $0.25 \mathrm{Na}-\mathrm{Z} 5$, scale bar, $M=50 \mathrm{~nm}$; (c) $0.5 \mathrm{Na}-Z 5$, scale bar, $\mathrm{M}=200 \mathrm{~nm}$; (d) $0.5 \mathrm{Na}-Z 5$, scale bar, $\mathrm{M}=50 \mathrm{~nm}$. 


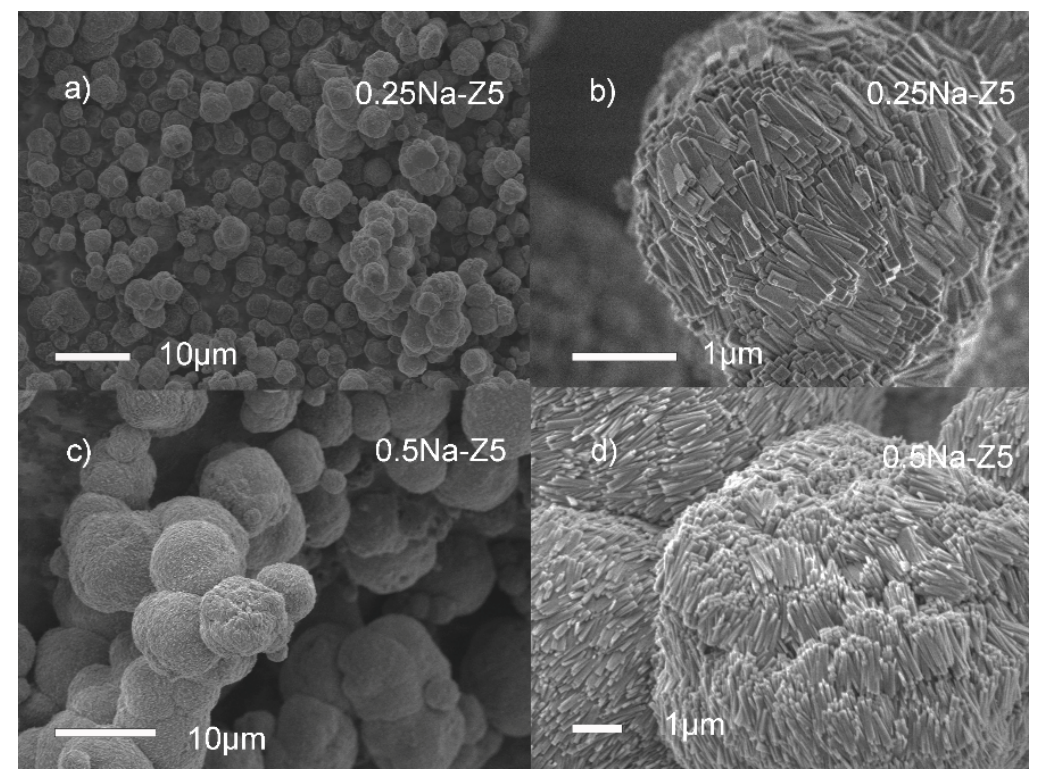

Fig. 5. SEM images of samples (a) $0.25 \mathrm{Na}-\mathrm{Z} 5$, scale bar, $\mathrm{M}=10 \mu \mathrm{m}$; (b) $0.25 \mathrm{Na}-\mathrm{Z} 5$, scale bar, $\mathrm{M}=1 \mu \mathrm{m}$; (c) $0.5 \mathrm{Na}-\mathrm{Z} 5$, scale bar, $\mathrm{M}=10 \mu \mathrm{m}$; and (d) $0.5 \mathrm{Na}-\mathrm{Z} 5$, scale bar, $\mathrm{M}=1 \mu \mathrm{m}$.

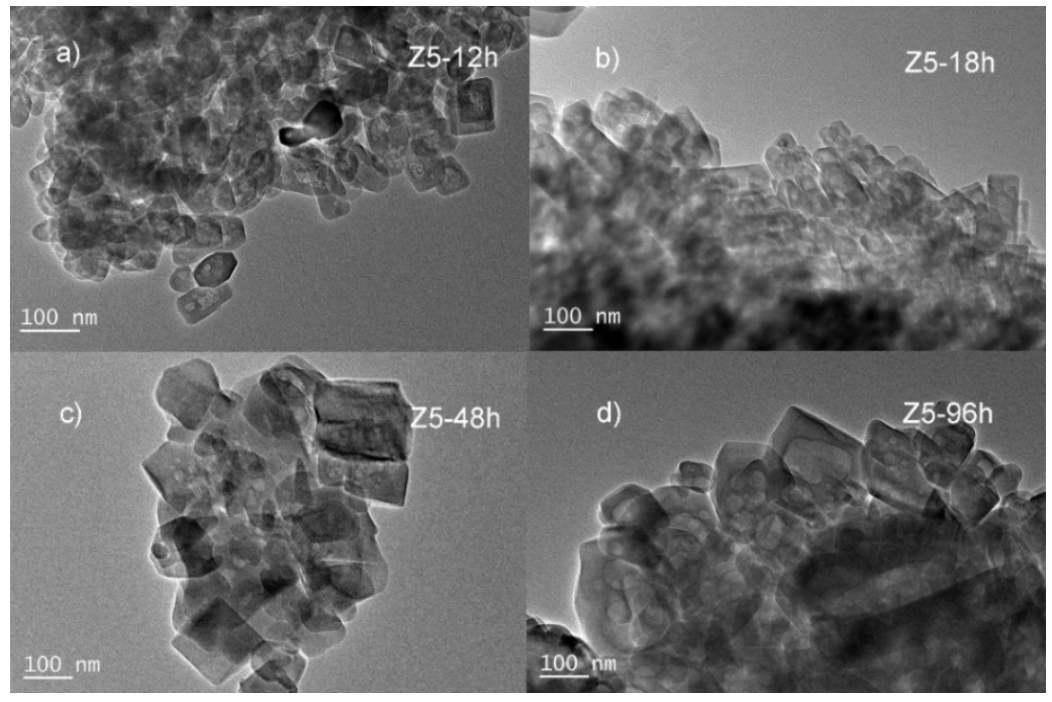

Fig. 6. TEM images of samples Z5-12h, Z5-18h, Z5-48h and Z5-96h synthesized for (a) 12h, (b) 18h, (c) 48h, and (d) $96 \mathrm{~h}$. Scale bar, $\mathrm{M}=100 \mathrm{~nm}$. 


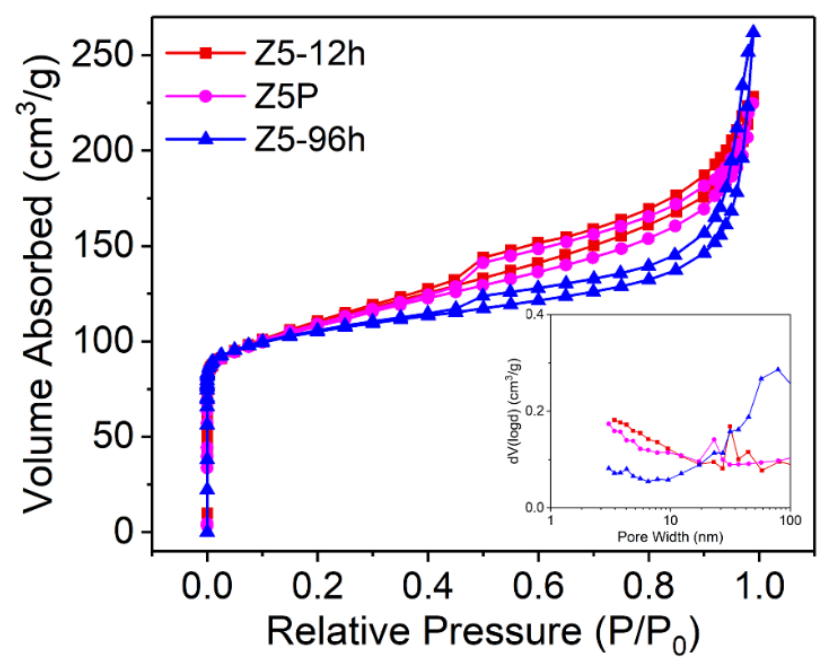

Fig. 7. $\mathrm{N}_{2}$-physisorption isotherms and BJH pore size distributions (Inset) of samples Z5-12h, Z5P and Z5-96h.

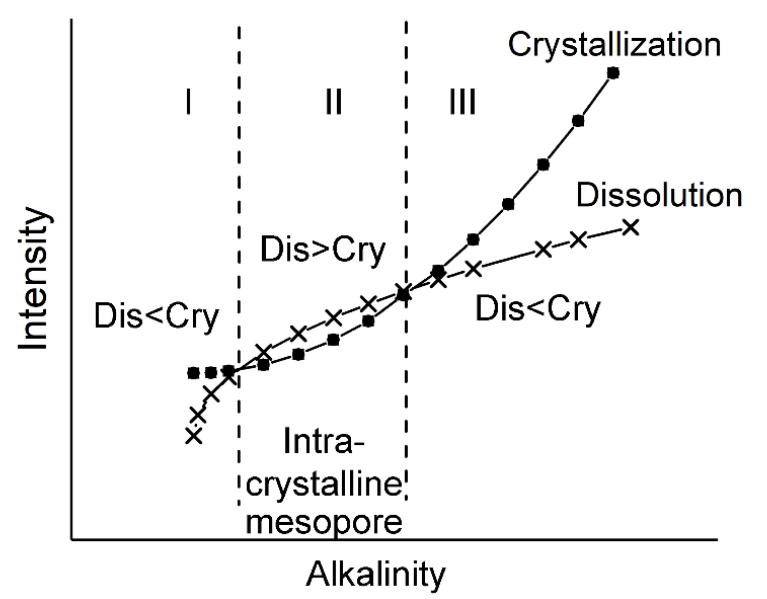

Scheme 1. Crystallization-dissolution of ZSM-5 zeolite imbalance as a function of $\mathrm{NaOH}$ concentration in the precursor gel subjected to GSM. Regions I and III: the crystallization is faster than the dissolution; Region II: the crystallization is slower than dissolution.

\section{Tables}

Table 1. Properties of samples prepared from precursor gels with different $\mathrm{Na} 2 \mathrm{O} / \mathrm{SiO}_{2}$ ratios and various crystallization time. 


\begin{tabular}{ccccc}
\hline Samples & $\mathrm{S}_{\text {BET }}\left(\mathrm{m}^{2} / \mathrm{g}\right)$ & $\mathrm{S}_{\text {meso }}\left(\mathrm{m}^{2} / \mathrm{g}\right)$ & $\mathrm{V}_{\text {total }}\left(\mathrm{cm}^{3} / \mathrm{g}\right)$ & $\mathrm{V}_{\text {meso }}\left(\mathrm{cm}^{3} / \mathrm{g}\right)$ \\
\hline Z5P & 393 & 77 & 0.35 & 0.20 \\
$1.5 \mathrm{Na}-\mathrm{Z} 5$ & 387 & 36 & 0.22 & 0.07 \\
$2.0 \mathrm{Na}-\mathrm{ZZ}$ & 370 & 13 & 0.17 & 0.03 \\
Z5-12h & 395 & 74 & 0.35 & 0.20 \\
Z5-96h & 396 & 49 & 0.41 & 0.26 \\
\hline
\end{tabular}

